\title{
DIREITO DOS ANIMAIS À LUZ DO DIREITO AMBIENTAL: USO DE ANIMAIS EM TESTE E PESQUISA CIENTÍFICA
}

\section{DERECHO DE ANIMALES EN LA LUZ DEL DERECHO AMBIENTAL : EL USO DE ANIMALES EN LA PRUEBA Y LA INVESTIGACIÓN CIENTÍFICA}

\author{
${ }^{1}$ Gustavo Silva Calçado \\ ${ }^{2}$ Zilah do Amor Cornélio
}

\section{RESUMO}

O presente artigo aborda a questão da pesquisa, bem como o sacrifício de animais em prol de análises e testes científicos. É dever do Estado promover a aplicação da proteção e segurança jurídica dos direitos da fauna com fulcro na legislação brasileira .Será explanado a base legal de proteção jurídica, no âmbito nacional, conferida ao animal, bem como relatará o surgimento da Lei $\mathrm{n}^{\mathrm{o}}$ 11.794/2008 e quais fundamentos são assegurados à proteção animal, bem como a função, princípios e comitês relacionados a ética animal. Por fim, os experimentos realizados atualmente nas indústrias de cosméticos e indústrias químicas. Abordaremos, ainda, os métodos alternativos e eficazes para substituir o uso direto de animais em testes científicos.

Palavras-chave: Animais, Direito, Métodos alternativos

\section{RESUMEN}

En este artículo se aborda el tema de la investigación, así como los sacrificios de animales en aras de un análisis científico y las pruebas. El Estado tiene el deber de promover la aplicación de la seguridad jurídica y la protección de los derechos de la fauna con punto de apoyo en la legislación brasileña .Será explicó el fundamento jurídico de la protección legal a nivel nacional, teniendo en cuenta que el animal e informe la aparición de la Ley $\mathrm{N}^{\circ} 11.794$ / 2008 y que los fundamentales están garantizados para la protección animal y la función, los principios y los comités relacionados con la ética animal. Por último, los experimentos realizados hoy en la cosmética y química. Nosotros, además, presente alternativas y métodos efectivos para reemplazar el uso directo de animales en pruebas científicas.

Palabras-claves: Animales, Derecho, Métodos alternativos

\footnotetext{
${ }^{1}$ Mestre em Direitos Coletivos e Cidadania pela Universidade de Ribeirão Preto - UNAERP, Ribeirão Preto - SP (Brasil) Professor da Universidade Tiradentes - UNIT, Aracaju - SE (Brasil).

E-mail: g.calcado1@gmail.com

${ }^{2}$ Graduada em Direito pela Universidade Tiradentes - UNIT, Aracaju - SE (Brasil).

E-mail: zilah.amor@hotmail.com
} 


\section{INTRODUÇÃO}

Visivelmente, a tecnologia junto às indústrias de cosméticos e medicamentos tem apresentado evolução com resultados eficazes perante a sociedade, entretanto se faz necessário refletir até que ponto esse avanço respeita o Direito dos Animais à luz do Direito Ambiental e quais os limites da utilização de animais em pesquisas científicas. Invariavelmente o uso destes seres vivos em comento agredirá a saúde e até mesmo a vida deles, pois os métodos utilizados proporcionam muitas vezes dor, sofrimento e até o descarte deles ainda em condições razoáveis de sobrevivência.

A problemática exposta incide: Ética Humana x Ética Ambiental: quais os limites da utilização de animais em pesquisas científicas? Demais disso, serão abordados os seguintes aspectos: Existe proteção jurídica conferido ao animal? O uso de animais para pesquisas fere a ética? E o que prevê alei 11.794/08 com relação a este assunto?

Objetiva-se buscar padrões razoáveis de soluções trazida pela Lei n ${ }^{\circ}$ 11.794/08, chamada de Lei Arouca, para a utilização de animais em pesquisa e teste científico, sugerindo outros meios legais para obtenção de resultados precisos sem agredir a fauna brasileira; em específico, analisar na legislação brasileira a proteção conferida a fauna; contextualizar a tutela do animal no cenário jurídico brasileiro; Estipular padrões entre o uso de animais em pesquisa e a ética científica.

No que diz respeito à metodologia prepondera utilização do método dialético, isso porque o presente artigo trará à desde a normatização legal do tema em análise, até que se apresente a conclusão decorrente de uma análise mais acurada do assunto.

\section{PROTEÇÃO JURÍDICA CONFERIDA AO ANIMAL NO CENÁRIO JURÍDICO BRASILEIRO}

É cediço que a fauna representa uma notória importância para um país, e nada mais justo do que promover a proteção desses seres viventes, imprescindíveis ao equilíbrio do ecossistema e, tangencialmente, da sobrevivência humana. Portanto, Milaré (2011, p. 299) assegura o apreço desta forma:

\footnotetext{
Parte integrante da biota e dos biomas, a fauna é um dos indicadores mais impressionantes da evolução da vida sobre a terra, desde os seres unicelulares aos organismos altamente complexos. A fauna seja nos respectivos habitats seja como componente do ecossistema terrestre, interagindo ou não com a flora, funcionam como um dos termômetros da biodiversidade na manutenção do equilíbrio ecológico.
} 
De acordo com a história do nosso país, a primeira garantia jurídica de proteção aos quadrúpedes foi divulgada ainda no governo de Getúlio Vargas, então Presidente do Brasil, na década de 30.

Assim, ocorreu o primeiro marco e o ponto propulsor para todas as outras medidas de proteção, no mês de julho do ano de 1934, através do Decreto n ${ }^{\circ} 24.645$, os maus tratos a animais tornou-se contravenção, e mais adiante, em 1941 na Lei de Contravenções Penais foi proibido praticar ato cruel contra animais.

A respeito do Decreto $\mathrm{n}^{\mathrm{o}} 24.645$, de 10 de Julho de 1934, inovações e medidas de proteção aos animais foram estabelecidas, foram elencadas penalidades para os maus tratos em animais, favorecendo, deste modo, a elevação e dignidade de vidas dos seres em comento, em consonância com o papel do Estado enquanto tutor dessa espécie.

É importante frisar que, em outubro de 1941, após a criação do Diploma legal em comento, houve a criação de outro Decreto-Lei $\mathrm{n}^{\circ} 3.688$, que foi nominado de "Lei das Contravenções Penais", por meio do qual foram revogados os artigos $2^{\circ}$, $8^{\circ}$, e 15 do Decreto $n^{\circ} 24.645 / 34$.

Em lugar do artigo $2^{\circ}$, passou a vigorar o artigo 64 do novel Decreto-Lei $\mathrm{n}^{\circ} 3.688$, que estatuiu como contravenção penal o abuso e as atrocidades perpetrados contra os animais, verbo ad verbum:

Art. 64 - Tratar animal com crueldade ou submetê-lo a trabalho excessivo: Pena - prisão simples, de 10 (dez) dias a 1 (um) mês, ou multa.

$\S 1^{\mathrm{o}}$ - Na mesma pena incorre aquele que, embora para fins didáticos ou científicos, realiza, em lugar público ou exposto ao público, experiência dolorosa ou cruel em animal vivo.

$\S 2^{\circ}$ - Aplica-se a pena com aumento de metade, se o animal é submetido a trabalho excessivo ou tratado com crueldade, em exibição ou espetáculo público".

Além da tipificação da crueldade contra os animais, o Diploma legal em comento também definiu os modos de assistência, reafirmando o dever do Estado na lida de tal preservação, assim como institui a Justiça Estadual como órgão competente para processar e julgar os casos de infração a essa norma.

\subsection{A proteção jurídica sob o olhar da carta de 1988}

O Direito Positivo Brasileiro, por meio da Constituição Federal de 1988, aprofundou as relações entre a infraestrutura econômica e o meio ambiente, e é considerada uma Constituição 
inovadora no aspecto de inserir no ordenamento jurídico a expressa proteção ao meio ambiente. Como prova disso, registra-se o artigo $5^{\circ}$, inciso LXXIII, ad litteram:

Art. $5^{\circ}$.Todos são iguais perante a lei, sem distinção de qualquer natureza, garantindose aos brasileiros e aos estrangeiros residentes no País a inviolabilidade do direito à vida, à liberdade, à igualdade, à segurança e à propriedade, nos termos seguintes: (omissis)

LXXIII - qualquer cidadão é parte legítima para propor ação popular que vise a anular ato lesivo ao patrimônio público ou de entidade de que o Estado participe, à moralidade administrativa, ao meio ambiente e ao patrimônio histórico e cultural, ficando o autor, salvo comprovada má-fé, isento de custas judiciais e do ônus da sucumbência;

Outrossim, com o fito de concretizar a proteção ambiental, foram elencadas obrigações para a sociedade e o Estado brasileiro, gerando segurança constitucional à fauna brasileira, por meio do estabelecimento harmônico entre os diferentes tipos de dispositivos voltados para a defesa do meio ambiente, fazendo a junção entre as normas de natureza econômica e as destinadas à proteção de direitos individuais, conforme demonstra o artigo

225 do Capítulo VI da Constituição vigente criada exclusivamente para legislar contra atos cruéis bem como a proteção ambiental:

Art. 225. Todos têm direito ao meio ambiente ecologicamente equilibrado, bem de uso comum do povo e essencial à sadia qualidade de vida, impondo-se ao Poder Público e à coletividade o dever de defendê-lo e preservá-lo para as presentes e futuras gerações. $\S 1^{\circ}$ - Para assegurar a efetividade desse direito, incumbe ao Poder Público:

I - preservar e restaurar os processos ecológicos essenciais e prover o manejo ecológico das espécies e ecossistemas; (Regulamento)

II - preservar a diversidade e a integridade do patrimônio genético do País e fiscalizar as entidades dedicadas à pesquisa e manipulação de material genético; (Regulamento) [...]

$[\ldots]$

VII - proteger a fauna e a flora, vedadas, na forma da lei, as práticas que coloquem em risco sua função ecológica, provoquem a extinção de espécies ou submetam os animais a crueldade. (Regulamento) [...]

Percebe-se que houve a preocupação do legislador constitucional em proteger o direito animal contra a extinção da fauna, em favor da preservação ecológica, além de coibir a submissão dos animais a tratamento cruéis. Sendo assim, outras modalidades do direito obedecem a princípios fixados na Constituição quando exercitam seu poder de punição contra o indivíduo em relação a prática da crueldade animais.

É facilmente perceptível que a partir dessa nova redação e conceituação de fauna, os animais não são mais considerados como objeto ou coisa. Essa evolução do direito animal ampara e respeita toda e qualquer vida até o fim, situação que enaltece a consciência do ser 
humano holisticamente considerado, isto é, num despertar de consciência da relevância da interdependência entre o homem e o meio ambiente para uma vida com qualidade.

\subsection{O caso dos beagles}

Não parou apenas nessas criações, atualmente novos projetos de lei são desenvolvidos nesse sentido. Um caso brasileiro, ocorrido no mês de outubro de 2013, gerou repercussão social e ficou conhecido como "Caso do Instituto Royal”, pois em suas pesquisas coelhos e cachorros da raça "beagle" eram reprimidos, padecendo a maus-tratos para serem submetidos nos testes de segurança de medicamentos para industrias.

Impulsionado por esse episódio, recentemente, no dia 04 de junho de 2014, a Câmara dos Deputados Federais aprovou o Projeto Lei no 2.905/2011, cujo conteúdo proíbe o uso de animais em testes de laboratório para fins de cosméticos, perfumes e produtos de higiene e limpeza, tenho seguido para o Senado apreciar o referido projeto que, dentre outras coisas, dispõe acerca da fixação de multa pecuniária cujo teto é o valor de $\mathrm{R} \$ 500.000,00$ (quinhentos mil Reais) para quem descumprir as determinações legais previstas pra a utilização de animais seja em testes, pesquisa ou até mesmo em ensinamentos biológicos em escolas e faculdades.

Sabe-se que vários julgamentos ainda são feitos e fundamentados no principio da insignificância quando relacionados a crimes contra animais, uma vez que as aplicações penais são muitas vezes brandas favorecendo assim a reincidência de crimes, no âmbito do Direito Ambiental.

Mesmo com o progresso legislativo, existe ainda um descaso quanto à proteção da fauna, pois há a falhas na fiscalização jurídica, fator esse que não deve servir de supedâneo para se relevar um assunto de tamanha importância como esse. Afinal, a existência saudável e equilibrada do ser humano depende do modo pelo qual se relaciona com os animais, razão pela qual impõe-se a proteção e o respeito aos direitos conferidos ao meio ambiente em geral e, mormente, aos bichos. 


\section{LEI No $11.794 / 2008$ E A ÉTICA ANIMAL}

\subsection{Sobre a Lei Arouca}

A Agência Fio Cruz, instituição oficial do Governo Federal Brasileiro, relatou a trajetória de vida do sanitarista Sérgio Arouca, um dos principais líderes que modificou o tratamento de saúde pública nesse País. Mesmo na ditadura militar, Arouca defendia o acesso de toda a população às informações científicas. E, dentre os grandes feitos deste cidadão, enquanto deputado federal, destaca-se a Lei Federal n 11.794/08, que incentiva a redução e a substituição do uso de animais em experimento científico.

Apesar de ter falecido em 02 de Agosto de 2003, seu legado perpetua-se e, hodiernamente é reconhecido pela produção científica e liderança em movimentos sociais em prol da melhoria da saúde no Brasil.

Aprovada pelo Senado Federal por unanimidade, em 09 de Setembro de 2008, a Lei $n^{\circ} 11.794$, recebeu a nomenclatura de Lei Arouca, revogou a Lei $n^{\circ} 6.638$ que estabelecia normas para a prática didático-científica da vivissecção de animais, inclusive dava permissão em todo território nacional à prática da vivissecção. Mas, graças a nova legislação, o uso de animais em experimentos científicos regulamentou etapas e procedimentos para proporcionar maior segurança jurídica à fauna.

Sirvinskas (2013, p.614) considera atividades de pesquisa todas que forem ligadas a ciência básica, aplicada, de desenvolvimento tecnológico de produção e controle que sejam testadas em animais.

Nesse sentido, a Lei vigente estabeleceu em seu artigo $4^{\circ}$, a criação do Conselho Nacional de Controle de Experimentação Animal- CONCEA, bem como a competência deste conselho no artigo $5^{\circ}$.

Nesse diapasão, o artigo $8^{\circ}$ da Lei Arouca, normatiza que o credenciamento das instituições com atividades de ensino ou pesquisa com animais deverão passar previamente, como condição indispensável de validade, pelas Comissões de Ética no Uso de Animais CEUAs. Devendo ainda, possuir o cadastro das Instituições de Uso Científico de Animais CIUCA e registro do credenciamento institucional para Atividades com Animais em Ensino ou Pesquisa - CIAEP.

Essa nova perspectiva de uso de animas para ensino e pesquisa no Brasil, trouxe normas, diretrizes e guias que visam orientar a todos que utilizam animais nessas áreas. 
Portanto, como regra geral, as Instituições deverão observar o estatuído no artigo 14 do referido Diploma legal:

Art. 14. O animal só poderá ser submetido às intervenções recomendadas nos protocolos dos experimentos que constituem a pesquisa ou programa de aprendizado quando, antes, durante e após o experimento, receber cuidados especiais, conforme estabelecido pelo CONCEA.

E, em caso de descumprimento ou irregularidade às normas, a lei Arouca determinou penalidades trazida pelo artigo colacionado abaixo, in verbis:

Art. 17. As instituições que executem atividades reguladas por esta Lei estão sujeitas, em caso de transgressão às suas disposições e ao seu regulamento, às penalidades administrativas de:

I - advertência;

II - multa de $\mathrm{R} \$ 5.000,00$ (cinco mil reais) a $\mathrm{R} \$ 20.000,00$ (vinte mil reais); III - interdição temporária;

IV - suspensão de financiamentos provenientes de fontes oficiais de crédito e fomento científico;

$\mathrm{V}$ - interdição definitiva.

Destarte, fica à cargo do art. 21 a definição da competência para físcalização das atividades reguladas pela Lei n ${ }^{\circ}$ 11.749/2008 aos órgãos dos Ministérios da Agricultura, Pecuária e Abastecimento, da Saúde, da Educação, da Ciência e Tecnologia e do Meio Ambiente, em suas respectivas áreas de competência.

\section{2. ÉTICA AMBIENTAL EM PESQUISAS}

\subsubsection{Princípios da pesquisa em animais}

$\mathrm{Na}$ atualidade existem princípios estabelecidos para direcionar a atividade de pesquisa científica usando animais. Esses princípios consideram os benefícios dos estudos para os seres humanos, justificando a utilização de animais, a valorização e as diferenças entre as espécies. Portanto, os projetos do meio científico de pesquisa que sejam classificados como inadequados de acordo com a moral e a ética não podem ser realizados. (MENESES,2002, p.106).

A utilização de animais em pesquisas deve pautar-se por alguns princípios norteadores, definidos por GOLDIM,1997: 
[...] os seres humanos são mais importantes que os animais, mas os animais também têm importância, diferenciada de acordo com a espécie considerada;

[...] nem tudo o que é tecnicamente possível de ser realizado deve ser permitido;

[...] nem todo conhecimento gerado em pesquisas com animais é plenamente aplicável ao ser humano;

[...] o conflito entre o bem dos seres humanos e o bem dos animais deve ser evitado sempre que possível. Desta forma, a utilização de animais em projetos de pesquisa deve ser uma alternativa ao uso de seres humanos e ser indispensável (p.ex.: ensino ou formação profissional), imperativa (p.ex.: câncer ou outras doenças graves) ou requerida (p.ex.: testes de novas drogas) [...].

O doutrinador elenca, ainda, critérios mínimos para usar animais na pesquisa:

- definir objetivos legítimos para a pesquisa em animais;

- impor limites à dor e ao sofrimento;

- garantir tratamento humanitário;

- avaliar previamente o projeto por um Comitê independente;

- fiscalizar instalações e procedimentos;

- garantir a responsabilização pública.

Principalmente os profissionais que usam animais em experimento científico, devem possuir a sensibilidade ao manejar as cobaias uma vez que, são suscetíveis a dor, angústia e percebem, assim como os humanos se estão sendo tratados com respeito e bem cuidados. (MENESES, 2002, p.107).

A revista "AMRIGS", 2002, trouxe outros fatores que contribuíram para a criação e estipulação de princípios de proteção. Afirma que o homem precisa do animal não apenas para se alimentar ou se vestir mas, também para o avanço da saúde, isto, apenas como justificativa para realização de estudos em animais.

Segundo o pesquisador Raymundo, 2002, em seu artigo “Os Deveres dos Pesquisadores para com os Animais de Experimentação", a pesquisa que utiliza animais deve estar de acordo com os padrões éticos estabelecidos pelos princípios adotados pelo COBEA- Sociedade Brasileira de Ciência em Animais de Laboratório

Percebe-se que após a criação desses princípios norteadores o direito animal tornou- se mais protegido e seguro quanto o uso de experimentação animal.

\subsubsection{Conselhos e comissões de ética animal}

Os comitês de ética surgiram no Brasil, na década de 90, e segundo o professor e doutor Stelio Pacca Loureiro Luna: “[..]são mantidos principalmente para assegurar o respaldo legal, as razões humanitárias, padronização, qualidade e publicação da pesquisa". (LUNA, 2004). 
Mas nesse período de eclosão dos conselhos éticos surgiram organizações abolicionistas que entendiam a função dos comitês como forma de legitimar o uso de animais e não como controle da pesquisa animal da melhor maneira possível, por isso opuseram-se a participar desse conselho ético.

Dentre os comitês criados por institutos de pesquisa e universidades, cujos regimentos internos possuem normas éticas relacionadas ao tratamento humanitário em experimentação animal, os principais foram:

- CETEA - FMRP/USP - Comissão de Ética em Experimentação Animal da Faculdade de Medicina de Ribeirão Preto da Universidade de São Paulo.

- CEUA - IB/UnB - Comitê de Ética no Uso Animal do Instituto de Ciências Biológicas (IB) da Universidade de Brasília.

- CEEA - IBB/UNESP - Comissão de Ética em Experimentação Animal do Instituto de Biologia e Biomédicas da Universidade do Estado de São Paulo, Botucatu/SP.

- CETEA - UFMG - Comissão de Ética em Experimentação Animal da Universidade Federal de Minas Gerais.

- CIUCA- Cadastro das Instituições de Uso Científico de Animais.

- CONCEA -Conselho Nacional de Controle de Experimentação Animal.

Independente de onde esteja a sede dos comitês de ética, o objetivo principal e unânime é assegurar que os animais quando manuseados para experimentação sejam mantidos e utilizados de maneira humanitária.

Dentre as funções inerentes a uma comissão, três pontos podem ser destacados:

- Revisão dos projetos. O comitê deve avaliar os projetos de pesquisa ou protocolos experimentais a fim de verificar se há necessidade daquela pesquisa ou procedimento, se o modelo animal proposto é o melhor modelo biológico, e assegurar que os animais não sofrerão dor ou estresse desnecessários. Para isso, os "3Rs" constituem-se na referência dos membros do comitê.

- Inspeções. Referem-se aos locais onde os animais são mantidos e locais dos experimentos.

- Proporcionar atendimento veterinário aos animais sempre que possível.

De acordo com a agencia Fio Cruz, o conceito definido para função dos comitês de ética animal:

[...] como instâncias de controle social, regulam as pesquisas que envolvem seres humanos e animais visando garantir o respeito e a prevenção de danos, além de dedicar a atenção necessária aos projetos que promovam intervenção no meio ambiente. Ciência e ética caminham juntas, em busca do crescente progresso sempre em benefício da humanidade e do planeta. 
Portanto, as comissões e comitês éticos são essenciais para aprovação, fiscalização de projetos que envolvem a utilização de animais em pesquisas científicas.

\section{EXISTE MÉTODO ALTERNATIVO PARA ANÁLISE CIENTÍFICA?}

A autorização para a realização de pesquisas científicas com/em animais foi pioneiramente prevista na Legislação brasileira, através da Lei nº 5.197/67, em seu artigo 14, que preceitua: "Poderá ser concedida a cientistas, pertencentes a instituições científicas, oficiais ou oficializadas, ou por estas indicadas, licença especial para a coleta de material destinado a fins científicos, em qualquer época."

Hodiernamente, são realizadas inúmeras pesquisas científicas em animais cuja finalidade é a aplicação dos resultados obtidos em atividades análogas nos seres humanos, ou seja, as pesquisas e experimentos têm como cobaia os animais para a utilização do produto testado em humanos e, para tanto, existem diversos tipos de experimento, como veremos na sequência do presente artigo.

\subsection{Tipos de Experimentos Realizados}

\subsubsection{Indústria cosmética}

A ANDA - Agência de Notícias de Direitos Animais, por meio do seu sítio eletrônico, apresentou uma notícia intitulada "Mais de 100 milhões de animais sofrem e morrem anualmente, vítimas da experimentação" e, infelizmente, é essa a realidade que se afigura, diaa-dia no cotidiano de milhões de animais, porquanto são submetidos a testes dolorosos que objetivam o teste de produtos simples que vão desde batons, sombras de olho até produtos para limpeza doméstica, tudo isso, para as indústrias determinarem se seus produtos são seguros para o uso humano, mas agindo de forma cruel com os cobaias.

Nesse sentido, Celso Antônio Pacheco Fiorillo conceitua cruel como a submissão do animal a um mal além do absolutamente necessário. (FIORILLO, 2010, p. 263).

Com base nos dados trazidos pelo artigo da Revista Brasileira de Ciências Farmacêuticas, os procedimentos mais comuns são:

a) Teste de Sensibilidade Cutânea (Draize Skin Test). 
No teste da sensibilidade, e realizado a retirada dos pelos para aplicar a substância a ser estudada. Aparentemente simples e indolor, mas desde a depilação até a obtenção da reação química do produto no animal, o sistema nervoso altera-se e enrijece a pele ocasionando ferimentos profundos.

Além de dolorosa, essa modalidade não apresenta um resultado totalmente seguro, visto que a pele humana é constituída de materiais genéticos diferentes dos animais de uso em laboratório.

b) Teste de Irritação Ocular (Draize Eye Test)

Tem por objetivo avaliar alterações oculares e perigos provocadas por produtos químicos. Em suma, geralmente esse procedimento utiliza coelhos, por serem dóceis e de custo baixo, estes ficam presos em caixas para imobilizarem o pescoço e as pálpebras a fim de aplicarem um pouco do produto a ser testado, sem qualquer uso de analgésico ou anestesia que amenize a dor, com contato direto as substância com o olho do animal.

Essa técnica pode durar vários dias incessantes de experimentação, o que causa sérias lesões chagando ate mesmo a cegueira do animal. Ocorre que esse método não deveria ser utilizado nem credibilizado uma vez que, os olhos do coelho possuem estrutura e fisiologia bem diferente dos olhos humanos, trazendo assim, uma margem de erro considerável.

c) 3 - DL50 (Dose Letal 50)

A prova consiste em forçar os bichos a ingerir uma determinada quantidade do elemento em estudo através de uma sonda gástrica, o que muitas vezes produz convulsões, sequelas e até mesmo a morte do animal por perfuração.

É chamado de DL50 porque a substancia é administrada até que cinquenta por cento do grupo experimental morra, caracterizando a dose letal para 50\% do grupo.

A finalidade dessa modalidade de experimento é a medição de toxicidade das substâncias no organismo, mas existem vários fatores como tipo de animal, tamanho, peso dentre outros que alteram o resultado tornando-o inseguro para os humanos.

\subsubsection{Indústria química}

A cada ano, surgem artefatos de vários tipos químicos para uso comercial, doméstico e pessoal e, sob o argumento de proporcionar uma maior eficácia dos produtos a ser comercializados, a experimentação animal tem sido o principal meio utilizado por empresas dessa categoria.

Sobre o assunto, colacionamos os seguintes relatos, in verbis: 
A experimentação animal é baseada em observações dos efeitos de substâncias sobre organismos vivos, ou na observação de mudanças comportamentais em organismos privados de nutrir-se, de maneira geral, com regiões nervosas extirpadas, e fora de seu habitat natural. O experimentador se vale então de técnicas fisiológicas ou bioquímicas, para obtenção de dados qualitativos ou quantitativos sobre a ação de medicamentos e substâncias. (RIVERA,2002).

A busca das empresas em tornar o elemento químico em aceitável e rendável tem se tornado constante para que haja uma aceitação social do seu produto, e é com fulcro nessa expectativa que as indústria químicas, farmacêuticas justificam a realização da vivissecção.

\subsubsection{Vivissecção}

Luís Paulo Sirvinskas, em seu livro "Manual de Direito Ambiental" define "vivissecção" como operação feita em animais vivos para todos estudo de fenômenos fisiológicos. (SIRVINSKAS, 2013, p.611).

A instituição Fio Cruz, do governo federal do nosso pais, conceitua vivissecção como sendo qualquer procedimento invasivo no animal, como a realização de uma cirurgia ou uma coleta de tecido. A vivissecção está sujeita às regras impostas pela legislação atual com relação à experimentação animal. (FIO CRUZ, 2014).

Por seu turno, a Pontifícia Universidade Católica do Rio de Janeiro- PUC, publicou um artigo científico intitulado "Vivissecção: crueldade ou ciência necessária" que traz o seguinte significado, ipsis litteris:

O termo vivissecção representa, em síntese, a dissecação anatômica ou qualquer operação congênere feita em animal vivo para estudo de algum fenômeno fisiológico. Trata-se, portanto, de um procedimento com finalidade científica utilizado com frequência em cursos voltados para área das ciências biológicas(...).

Existem normas que regulamentam a vivissecção, como é exemplo a Lei 6.638/79 que, não obstante, também elenca as hipóteses em que a referida prática é proibida, ad litteram:

Art. $3^{\circ}$ - A vivissecção não será permitida: I- sem o emprego de anestesia;

II - em centros de pesquisas e estudos não registrados em órgãos competentes; III - sem a supervisão de técnico especializado;

IV - com animais que não tenham permanecido mais de 15 dias em biotérios legalmente autorizados;

$\mathrm{V}$ - em estabelecimentos de ensino de primeiro e segundo graus e em quaisquer locais frequentados por menores de idade. 
Na mesma linha de intelecção, a Lei de Crimes Ambientais (Lei nº 9.605/98), no que se refere a experimentação animal, avalia como crime a vivissecção nas seguintes situações, verbo ad verbum:

Art. 32 - Praticar ato de abuso, maus-tratos, ferir ou mutilar animais silvestres, domésticos ou domesticados, nativos ou exóticos:

Pena: detenção, de três meses a um ano, e multa.

$\S 1^{\circ}$ incorre nas mesmas penas quem realiza experiência dolorosa ou cruel em animal vivo, ainda que para fins didáticos ou científicos, quando existirem recursos alternativos; $\S 2^{\circ}$ - a pena será aumentada de um sexto a um terço, se ocorre a morte do animal.

Sobre a realização do procedimento de vivissecção, posicionam-se três correntes, a saber, os vivisseccionistas, os abolicionistas e os defensores da doutrina dos 3 R's (Reduzir, Reutilizar e Reciclar).

A primeira corrente, a dos vivisseccionistas, defende que os benefícios ultrapassam os malefícios causados aos animais e que a cura para as doenças dependem de tais procedimentos realizados. Defende, ainda, que pelo menos duas instituições brasileiras de ensino são adeptas da vivissecção, a Universidade Federal Rural do Rio de Janeiro e a Universidade de Brasília, bem como indústrias químicas, alegando que é importante para os alunos em formação, a realização de experimentos em animal vivo.

Um chocante depoimento sobre essa técnica é do cientista e médico cardiologista do Instituto do Coração (InCor) de São Paulo, Marcelo Andrade. O ativista relata, por meio do sítio eletrônico "Interniche Brasil", uma experiência vivida durante a faculdade para defender que a ciência não precisa da vivissecção, ad litteram:

Quem já viveu a dura experiência de encarar um cão subanestesiado tendo suas vísceras extraídas, e ao olhar seu olhos ver lágrimas, apenas lágrimas como manifestação de dor, já que toda sua musculatura está paralisada pelos bloqueadores neuromusculares, sabe exatamente do que estou falando.

Por sua vez, a segunda corrente, a abolicionista, ao contrário da primeira corrente e fazendo jus a nomenclatura recebida, almeja abolir totalmente a prática de cortar o animal vivo para realizar experimentos, por se tratar de um meio cruel para obtenção de efeitos aproximados, sendo que existem métodos alternativos que proporcionam resultado eficaz sem precisar maltratar os cobaias.

$\mathrm{O}$ artigo finaliza explicando que a última linha de pensamento, intitulada como dos três R's, tem sua origem em uma obra americana intitulada “The Principles of Humane Experimental Technique” (Russel \& Burch, 1959) que possui como pilar a substituição, a redução e o 
refinamento. Tudo isso para propor a diminuição de cobaias em experimentos evitando assim o sofrimento causado a eles.

\subsubsection{Outras experiências}

Os estudos psiquiátricos com cobaias animais, são realizados para averiguarem quais fatores ocasionam o transtorno mental, afim de que sejam contornados, afirma o Instituto Oswaldo Cruz-Fiocruz do Rio de Janeiro.

A Sociedade de Psicologia Experimental, impõem condições para que esses experimentos possam ser realizados. Portanto, “[...] os pesquisadores devem usar o menor número de animais necessários, e devem manter dano físico ou psicológico a um mínimo absoluto de acordo com as necessidades dos objetivos da pesquisa." Ademais, a pesquisa deverá informar se é uso legítimo da ciência para beneficiar a sociedade.

Um dos artigos científicos básicos no presente estudo, “A Verdadeira Face Da Experimentação Animal”- Sua Saúde em perigo, dos renomados pesquisadores e biólogos, Sérgio Greif \& Thales Tréz, divulgado pela Sociedade Educacional Fala Bicho (2000), traz em seu conteúdo algumas formas de experimentos realizados em animais, cuja finalidade é de estudo comportamental e psiquiátrico:

a) Doenças mentais

Uma das maneiras de terapia para doenças mentais é o choque elétrico. Os cientistas descobriram através de experimentos em animais que o micro choques suspendem gradualmente ou imediatamente a reação de crise do individuo que sofrem de amnésia, dependência, hipotensão, delírios, depressão e suicídio.

b) Cirurgias experimentais

É cada vez mais presente em cursos de saúde, a experimentação de técnicas laboratoriais e de cirurgias em bichos principalmente cães, gatos, macacos e porcos, cuja esperança é que haja avanços na saúde humana advindo de estudos feitos com outros animais. Ocorre que, quando procedido em humanos pela primeira vez, geralmente os efeitos apresentam-se diferentes daqueles observados nos exames feitos em animais. Portanto, não é a melhor maneira de se aprimorar da medicina humana, através da prática vivisseccionista.

c) Comportamento e aprendizado

Outra modalidade usada pelos especialistas na tentativa de estudar os comportamentos humanos como agressividade, aprendizado, reações psicológicas dentre outros, 
também são usados bichos para compreensão comportamental humana frente a situações cotidianas que são submetidos diariamente. Experimentos como usar animais são descerebrados e colocados em obstáculos para encontrarem o lugar de saída; macacos esfomeados, com fios ligados ao cérebro, são obrigados a procurar a comida, caso errem recebem choque elétrico; gatos operados e reduzidos a um estado meramente vegetativo são deixados durante dias inteiros em equilíbrio, sobre plataformas cercadas de água, para evitar que durmam, com objetivo de registro de suas reações durante a vigília.

São testes que infelizmente, maltratam mais do que ajudam a entender o comportamento humano, que por serem seres dotados de inteligência, se auto governarem, tendem a agir de acordo com seus pensamentos ou com interferência da social.

d) Experimentos com álcool e tabaco

Por mais que já se tenha comprovação que a ingestão do álcool afeta a saúde dos fetos humanos, ainda existem experimentos com fetos de bichos, geralmente de camundongos, ainda hoje infelizmente são realizados. Além disso, não há mais sentido em observar o comportamento agressivo de animais após consumo etílico, uma vez que já foi comprovado que o álcool afeta diferentes pessoas de modos diferentes.

Há, ainda, aqueles experimentos em que os "animais são forçados a inalar fumaça de cigarro ou ingerir álcool para o estudo dos efeitos de suas substâncias no organismo", quando tais efeitos já são mais do que conhecidos (GREIF e TRÉZ, 2000, p. 35).

O Portal Mercado Ético, trouxe em seu artigo intitulado "Brasileiros finalmente debatem testes em animais", a expressão do renomado neurocientista canadense Philip Low sobre esse assunto, “O mundo gasta 20 bilhões de dólares por ano matando 100 milhões de vertebrados em pesquisas médicas. A probabilidade de um remédio advindo desses estudos ser testado em humanos (apenas teste, pode ser que nem funcione) é de 6\%. É uma péssima contabilidade."

Por isso, hoje em dia, existem métodos são chamados de "Métodos Alternativos à Experimentação Animal”.

\subsection{As Alternativas}

Vejamos algumas técnicas alternativas trazidas pelo livro "Animais de laboratório criação e experimentação", publicado pela Editora Fio Cruz, bem como afirmações trazidas pelos dos renomados biólogos Sérgio Greif \& Thales Tréz: 
a) Tecnologia in vitro

Na página 55 do livro científico, “A Verdadeira Face Da Experimentação Animal”Sua Saúde em perigo, uma das técnicas alternativas apresentadas é o experimentos in vitro, procedimento conceituado como adequados para algumas áreas da biologia, por exemplo na pesquisa de câncer; imunologia, testes de tóxicos, fabricação de vacinas; estudo de doenças infecciosas; estudo de doenças, dentre outros.

Segundo o biólogo Greif, em entrevista a "Cruzeiro sul” em novembro de 2013, afirmou que "Os testes in vitro em frascos de co-cultura são bem específicos e utilizam várias linhagens diferentes de células interagindo da mesma forma como fariam no corpo como um todo".

Assegurando que na pesquisa de câncer o avanço refere-se na aplicação dos anticorpos monoclonais, é menos tóxica em comparação com os procedimentos utilizados na atualidade como quimioterapia e radioterapia. Já na produção das vacinas, o uso no tecido humano e mais seguro que aplicado em animais evitando assim a contaminação por vírus advindos dos animais prejudiciais aos humanos.

b) Simulações em computadores

Com o avanço tecnológico, nasce a esperança de ser possível a simulação de reação química através dos computadores. Nesse sentido o médico, Ray Greek, prestou depoimento entrevista ao endereço eletrônico "Vista-se", cujo endereço é http://vista-se.com.br/3-motivospara-ser-contra-testes-em-animais/ que: “As drogas deveriam ser testadas em computadores, depois em tecido humano e daí sim, em seres humanos. Empresas farmacêuticas já admitiram que essa será a forma de testar remédios no futuro".

Nesse sentido, GREIF e TRÉZ (A verdadeira face da experimentação animal, 2000) asseveram que, ainda, que as simulações em computadores têm sido utilizados para a avaliação da toxicidade de substâncias, eliminando os testes LD50 em animais. Dessa forma, surgem testes inovadores e confiáveis de drogas combatentes a AIDS e anti-cancerígenas.

Segundo o Portal Mercado Ético, em seu artigo intitulado "Brasileiros finalmente debatem testes em animais", está evidenciado o seguinte posicionamento, verbo ad verbum:

\footnotetext{
Um exemplo da aplicação de métodos alternativos, no caso do ensino, é o da Faculdade de Medicina da Universidade Federal do Rio Grande do Sul (FAMED/UFRGS), que em abril de 2007 tornou-se a primeira faculdade de medicina do Brasil a abolir totalmente o uso de animais na graduação, no que foi seguida logo depois pela Faculdade de Medicina do ABC (SP).
}

Por meio desse recurso computadorizado, os experimentos e a aprendizagem abriu uma alternativa para aposentar o método tradicional. 


\subsection{Métodos Alternativos Na Pesquisa}

Fazendo um contraponto aos procedimentos comuns elencados, neste trabalho, no subitem 3.1, teremos:

\subsubsection{Contra irritação ocular}

\subsubsection{Teste draize}

Consiste em criar uma córnea artificial com aparência e funcionamento muito semelhantes aos da natural. A córnea artificial foi desenvolvida pelos Canadenses com os usos de células humanas e desenvolvida com técnicas de engenharia genética.

Em estudo publicado na revista científica americana Science, os cientistas disseram “que podem produzir córneas a partir de uma pequena amostra de células humanas". Eles ressaltam que "ainda levará alguns anos antes que seres humanos possam se beneficiar da córnea feita em Laboratório". O implante, porém, já tem uma aplicação imediata: testar a sensibilidade dos olhos a medicamentos e produtos químicos, livrando os coelhos da crueldade imposta pelo teste Draize. (GREIF \& TRÉZ, 2000, p.66).

\subsubsection{Eytex}

Produzido também na Califórnia, eytex é um procedimento in vitro que mede a irritação ocular através de sistema de alteração protéica. É composto por "uma proteína vegetal obtida da semente de feijão mimetiza a reação da córnea a substâncias estranhas."

O artigo informa que esse método é usado pela Avon como alternativa ao cruel teste Draize. (GREIF \& TRÉZ, 2000, p.64).

\subsubsection{Contra irritação cutânea}

\subsubsection{Skintex}

É um método in vitro para avaliar irritação cutânea, usando a casca da semente de abóbora para mimetizar a reação de substâncias estranhas sobre a pele humana (tanto o Eytex como Skintex podem testar 5.000 materiais diferentes). (SÉRGIO GREIF \& THALES TRÉZ, 2000, p.64) 


\subsubsection{Testskin}

Produzido em Massachusetts, o Testskin "utiliza pele humana cultivada em saco plástico estéril, podendo ser usado para medir o grau de irritação cutânea (método usado pela Avon, Amway, e Estee Lauder)". (GREIF \& TRÉZ, 2000, p.64). 3.3.2.3 Alternativa ao DL 50

A obra científica traz que o professor Heinrich Koch, da Universidade Viena, disse:

"Estávamos procurando métodos alternativos tão significativos quanto os experimentos em animais, mas sem usar criaturas vivas, sensíveis à dor."

O método encontrado foi "o uso de levedo de cerveja comum, em vez de ratos, camundongos e cobaias para determinar a toxicidade de medicamentos e outras substâncias químicas.” Afirma o professor: "A medida que indica dose letal de uma substância (DL 50) concentração que mataria a metade dos animais testados - é a mesma concentração que impede metade das células do levedo de se reproduzirem”. Fonte: World Monitor Magazine (GREIF \& TRÉZ, 2000, p.65).

\section{CONSIDERAÇÕES FINAIS}

O presente artigo abordou a conscientização social no que se refere ao uso de animais em testes e experimentos científicos.

O meio social foi transformado e a visão dos animais como "objeto" foi modificado recebendo atenção devida com a criação de legislações providenciando a proteção jurídica da melhor forma possível. A aplicação de leis para combate as práticas delituosas contra a fauna com a finalidade de proteger a vida animal assim como preservando o equilíbrio ambiental do olhar cego das indústrias que só pensam no crescente busca pelo lucro.

Ocorre que, atualmente, há opções que não utilizam animais em experimentos dolorosos. Por mais que esses métodos sejam divulgados e acessíveis às indústrias e instituições de ensino, elas não adotam tais medidas porque seu custo é mais alto e não rentável, preferindo assim, a forma comum de cultivo de animais em laboratório visando a praticidade.

Seria interessante que as instituições de ensino e os pesquisadores optassem pela aplicação dos métodos alternativos assegurando a ética animal bem como a preservação da fauna.

Cabe aqui, um pedido a sociedade, que agora sabendo do sofrimento e agressões causadas pelas empresas de cosmético, farmacêutica, industrial como um todo, proporcionam 
aos seres indefesos na busca incessante de lucro sem importar na crueldade que causa, que evitem o uso de marcas e produtos que testam seus produtos em animais, mesmo que sendo minoria mas que seja oposição e não compactue com a compra de produtos.

Conclui-se que a implantação de métodos alternativos no experimento científico representará o fim do sofrimento de milhares de animais e o início de um processo mais ético na educação e na pesquisa.

\section{REFERÊNCIAS}

ACADEMIA BRASILEIRA DE CIÊNCIAS. Home Page. Carta do CONCEA esclarece sobre $\begin{array}{ll}\text { experimentação } & \text { com } \\ \text { http://www.abc.org.br/article.php3?id_article=2948 } & \text { >nimais. Acesso em: 07.nov.2014. }\end{array}$

AGÊNCIA FIO CRUZ DE NOTÍCIAS. Home Page. Experimentação Animal. Perguntas e Respostas. Disponível em: < http://www.agencia.fiocruz.br/perguntas-e-respostas >. Acesso em: 30.out.2014.

BRASIL. Constituição (1988) Constituição da República Federativa do Brasil. Diário Oficial [da] República Federativa do Brasil, Brasília, DF. 5 out. 1988. Disponível em: <http://www.planalto.gov.br/ccivil_03/constituicao/constitui\%C3\%A7ao.htm>. Acesso em: 08 jun.2014.

. Lei $\mathbf{n}^{\mathbf{0}}$ 6.938, de 31 de agosto de 1981. Dispõe sobre a Política Nacional do Meio

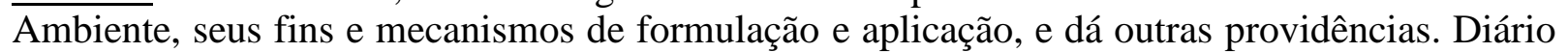
Oficial [da] República Federativa do Brasil, Brasília, DF. Disponível em: <http://www.planalto.gov.br/ccivil_03/leis/16938.htm>. Acesso em: 08 jun.2014.

Decreto-lei $\mathbf{n}^{\mathbf{0}}$ 3.688, de 3 de outubro de 1941. Lei das Contravenções Penais. Diário Oficial [da] República Federativa do Brasil, Brasília, DF. Disponível em: <http://www.planalto.gov.br/ccivil_03/decreto-lei/del3688.htm>. Acesso em: 08 jun.2014.

Lei $\mathbf{n}^{\mathbf{0}}$ 9.605, de 12 de fevereiro de 1998. Dispõe sobre as sanções penais e administrativas derivadas de condutas e atividades lesivas ao meio ambiente, e dá outras providências. Diário Oficial [da] República Federativa do Brasil, Brasília, DF. Disponível em: <http://www.planalto.gov.br/ccivil_03/leis/19605.htm >. Acesso em: 08 jun.2014.

. Decreto no 24.645, de 10 de Julho de 1934, de Getúlio Vargas. Estabelece Medidas de Proteção aos Animais. Diário Oficial da República Federativa do Brasil, Brasília. Diário Oficial [da] República Federativa do Brasil, Brasília, DF. Disponível em: < http://legis.senado.gov.br/legislacao/ListaPublicacoes.action?id=39567>. Acesso em 08 jun.2014.

Lei $\mathbf{n}^{\mathbf{0}}$ 11.794, de 08 de outubro de 2008. Regulamenta o inciso VII do $\S 1^{\underline{o}}$ do art. 225 da Constituição Federal, estabelecendo procedimentos para o uso científico de animais; revoga a Lei $\mathrm{n}^{\underline{0}}$ 6.638, de 8 de maio de 1979; e dá outras providências. Diário Oficial [da] 
República Federativa do Brasil, Brasília, DF. Disponível em: < http://www.planalto.gov.br/ccivil_03/_Ato2007-2010/2008/Lei/L11794.htm\#art27>. Acesso em: 07.nov.2014.

Lei $\mathbf{n}^{\circ}$ 5.197, de 3 de janeiro de 1967. Dispõe sobre a proteção à fauna e dá outras providências. Diário Oficial [da] República Federativa do Brasil, Brasília, DF. Disponível em: <http://www.planalto.gov.br/ccivil_03/leis/15197.htm>. Acesso em: 08 jun.2014.

CHAVES, Fábio. Três motivos para ser contra testes em animais. Disponível em: < http://vistase.com.br/3-motivos-para-ser-contra-testes-em-animais/>. Acesso em: 30.out.2014.

FIORILlO, Celso Antônio Pacheco. Curso de Direito Ambiental Brasileiro. $11^{\mathrm{a}}$ ed. revista, atualizada e ampliada. São Paulo: Saraiva, 2010. p. 116; 255.

GREIF, Sérgio. A experimentação animal e as leis. Disponível em: <http://www.anda.jor.br/11/12/2008/a-experimentacao-animal-e-as-leis $>$. Acesso em: 07.nov.2014.

GREIF, Sérgio; TRÉZ, Thales. A verdadeira face da experimentação animal.

Rio de Janeiro: Sociedade Educacional "Fala Bicho", 2000.

GOLDIM JR, Raymundo MM. Pesquisa em Saúde e os Direitos dos Animais. 2 ed. Porto Alegre: HCPA; 1997.

LACERDA, Gabriela Farias. Vivissecção: crueldade ou ciência necessária? Uma análise jurídica sobre o uso de animais para práticas experimentais e didáticas. Disponível em: $<$ http://www.pucrio.br/pibic/relatorio_resumo2013/relatorios_pdf/ccs/DIR/DIRGabriela\%20Lacerda.pdf>. Acesso em: 30.out.2014.

LUNA, S.P.L. Como se Estrutura uma Comissão de Ética em Universidades. In: Simpósio sobre Alternativas ao Uso de Animais em Pesquisas e Ensino, São Paulo, 3 e 4 de set. 2004. Anais do I Simpósio sobre Alternativas ao Uso de Animais em Pesquisas e Ensino. São Paulo: USP, 2004. p. 15-23.

MARTONI, Lígia. Vivisecção nas Universidades do Paraná. Disponível em: http://www.internichebrasil.org/noticias2.htm\#gazeta> Acesso em: 30.out.2014.

MENESES, Honório Sampaio. Simpósio sobre Ética. Ética e pesquisa em animais. Disponível em: <http://www.amrigs.com.br/revista/4603/\%C3\%89tica\%20e\%20pesquisa\%20em\%20animais. pdf> Acesso em: 03.nov.2014.

. Ética da pesquisa em animais. Revista AMRIGS. Porto Alegre, v. 46, n 3,4, p 105 $\overline{108, \text { jul-dez } 2002 .}$

MILARÉ, Édis. Direito do Ambiente. A Gestão Ambiental em Foco. $7^{\mathrm{a}}$ ed. revista. São Paulo: Revista dos Tribunais,2011.p.152;153;299;300;303;305.

MULLER. Fernanda B. Brasileiros finalmente debatem testes em animais. Disponível em: $<$ http://www.mercadoetico.com.br/arquivo/brasileiros-finalmente-debatem-testes-em- 
animais/>. Acesso em: 01.11.2014

RAYMUNDO MM. Os Deveres dos Pesquisadores para com os Animais de Experimentação: uma proposta de auto-regulamentação. [dissertação]. Porto Alegre: Programa de Pós-Graduação em Ciências Biológicas: Fisiologia/Universidade Federal do Rio Grande do Sul; 2000.

SIRVINSKAS, Luís Paulo. Tutela penal do meio ambiente: breves considerações atinentes à lei n. 9.605 de 12 de fevereiro de 1998. 2.ed. São Paulo: Saraiva, 2002. p.130. 